\title{
The Promising Synthetic Route Hydrothermal Synthesis of Non-Stoichiometric Cerium and Boron Containing Compounds and Characterization
}

\author{
G. ÇELIK* AND F. KurTuluş
}

Balikesir University, Science and Art Faculty, Chemistry Department, Cagis Yerleskesi 10145 Balikesir, Turkey

Cerium, the most abundant rare earth element, and boron containing mineral (lithium tetraborate pentahydrate) were used for synthesizing rare earth borates. Alternatively, for preparing rare earth borates, hydrothermal technique can be used. The non-stoichiometric cerium and boron containing compounds were synthesized by hydrothermal method using cerium sulphate and lithium tetraborate pentahydrate in appropriate molar ratio. Characterizations were done by X-ray diffraction, Fourier transform infrared spectroscopy, scanning electron microscopy/energy dispersive X-ray analysis, and thermogravimetric/differential thermal analysis.

DOI: $10.12693 /$ APhysPolA.125.325

PACS: 82.33.Pt, 61.66.Fn, 61.05.cp

\section{Introduction}

Boron, which most of the countries around the world want to have today, is a sideburns element due to exhibiting too many remarkable properties. The best known boron containing compounds are borate crystals to be promising materials as non-linear optics, piezoelectric, scintillators, and phosphors [1, 2]. On the other hand, the rare earth elements (REE) and their compounds are the common subject of the world like borates. The luminescent properties of rare earth doped metal borate phosphors have been well examined [3-6]. Cerium, the most abundant rare earth metal, is generally used for doping process to synthesis rare earth borate phosphors $[7,8]$. The materials containing both boron and a REE are candidate in especially phosphors and many other areas, for instance catalysts, fluorescence and laser applications, high temperature and scintillation techniques $[3,9]$. Usually, these types of compounds are synthesized by solid state reaction from oxide precursors at high temperatures and several intermediate grindings, alternatively wet-chemical synthesis route [7, 10-15].

We aimed to synthesis of rare earth borate, not rare earth doped metal borate. For the purpose of obtaining REE borate, cerium sulphate and lithium tetraborate pentahydrate were used as raw materials, and non-conventional synthesis route, hydrothermal method was applied.

\section{Experimental procedure}

\subsection{Synthesis of non-stoichiometric cerium borate}

$\mathrm{Ce}_{0.1} \mathrm{~B}_{4.65} \mathrm{O}_{8.18}$ was synthesized by dissolving cerium sulphate and lithium tetraborate pentahydrate in the high pure water with appropriate molar ratio. The homogeneous solution was put into a stainless-steel teflon autoclave and heated 3 days $(72 \mathrm{~h})$ at $170^{\circ} \mathrm{C}$. The product was washed by high pure water for removing excessive

\footnotetext{
*corresponding author; e-mail: gulsahcelik9@gmail.com
}

material, dried at $70^{\circ} \mathrm{C}$ for $2 \mathrm{~h}$ and homogenized in an agate mortar.

\subsection{XRD, FTIR, DT/TGA and SEM/EDX analyses}

Characterization studies were performed by PANanalytical X'Pert PRO Diffractometer (XRD) with $\mathrm{Cu} K_{\alpha}$ (1.5406 $\AA, 45 \mathrm{kV}$ and $30 \mathrm{~mA}$ ) radiation. The Fourier transform infrared (FTIR) spectrum was taken on a Perkin Elmer Spectrum 100 FTIR Spectrometer from 4000 to $650 \mathrm{~cm}^{-1}$. Thermogravimetric-differential thermal analysis (TG/DTA) was carried out by Perkin Elmer Diamond TG/DTA. Morphological properties and semi-quantitative analyze of the sample were realized by ZEISS Supra 40 VP. The Binder ED 53/E2 furnace and the hydrothermal container of Parr Instrument Company were used.

\section{Results and discussion}

The X-ray powder diffraction pattern of the sample is displayed in Fig. 1. There are no coupling between

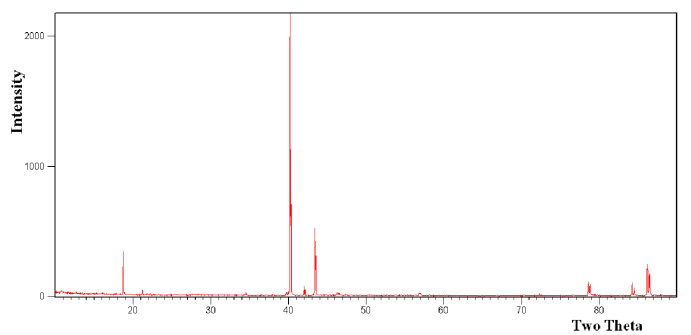

Fig. 1. Powder XRD pattern of $\mathrm{Ce}_{0.1} \mathrm{~B}_{4.65} \mathrm{O}_{8.18}$.

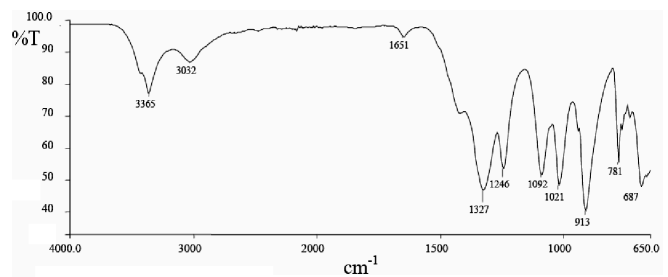

Fig. 2. FTIR spectrum of $\mathrm{Ce}_{0.1} \mathrm{~B}_{4.65} \mathrm{O}_{8.18}$. 
ICDD cards (International Card for Diffraction Data) and the sample's pattern. Therefore, we refer to solve the crystal structure by semiquantitative analysis obtained by scanning electron microscopy/energy dispersive X-ray (SEM/EDX) analysis.

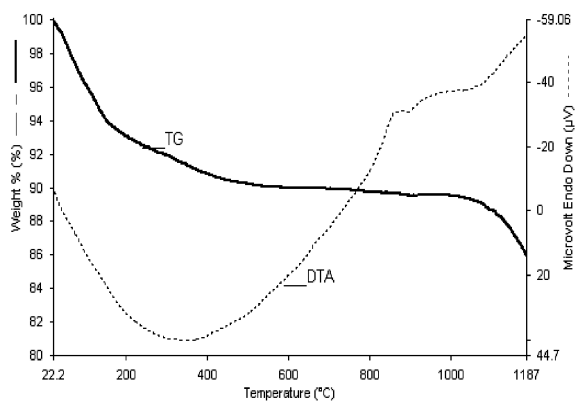

Fig. 3. TG/DTA curve of $\mathrm{Ce}_{0.1} \mathrm{~B}_{4.65} \mathrm{O}_{8.18}$.

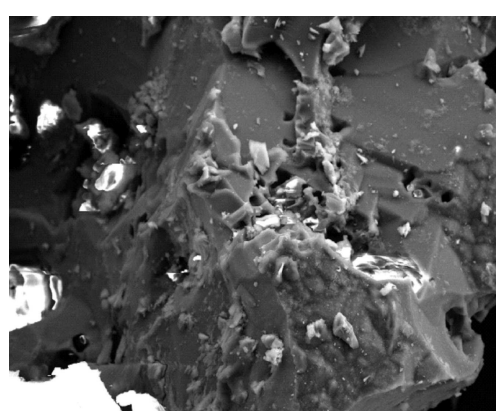

Fig. 4. SEM micrograph of $\mathrm{Ce}_{0.1} \mathrm{~B}_{4.65} \mathrm{O}_{8.18}$.

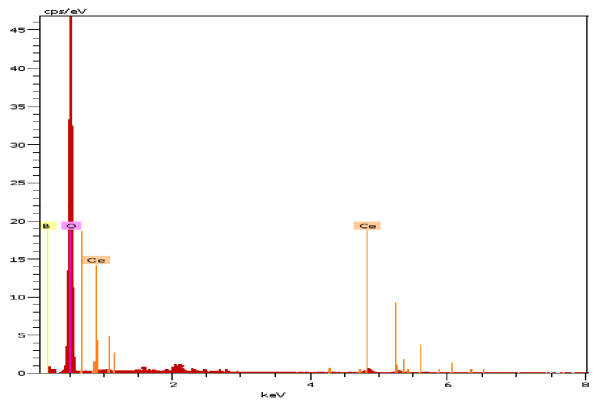

Fig. 5. EDX result of $\mathrm{Ce}_{0.1} \mathrm{~B}_{4.65} \mathrm{O}_{8.18}$.

An FTIR spectrum of the product is exhibited in Fig. 2. The peaks at $1021-1651 \mathrm{~cm}^{-1}$ and $781-1246 \mathrm{~cm}^{-1}$ are characteristic peaks of $\mathrm{BO}_{2}$ and $\mathrm{BO}_{3}$ groups, respectively $[16,17]$. The absorption band observed at $3365 \mathrm{~cm}^{-1}$ proves the presence of crystal water.

Thermal analysis results of $\mathrm{Ce}_{0.1} \mathrm{~B}_{4.65} \mathrm{O}_{8.18}$ is given in Fig. 3. TG/DTA spectrum is taken in the temperature range of 24 to $1187^{\circ} \mathrm{C}$. The graphics show that the sample is quite stable owing to $10 \%$ mass loss in this field.

Figure 4 is the SEM micrograph of $\mathrm{Ce}_{0.1} \mathrm{~B}_{4.65} \mathrm{O}_{8.18}$. The figure supports crystallization of the sample, and also demonstrates cerium ions entering into the structure.
The results of EDX analysis is given in Fig. 5. Yellow, pink, and orange lines correspond with $\mathrm{B}, \mathrm{O}$, and $\mathrm{Ce}$, respectively. The small peaks near $2 \mathrm{keV}$ become involved with platinum used covering the sample. The results are taken into account; the combination ratio of the elements was calculated as 0.1:4:65:8.18.

\section{Conclusions}

Non-stoichiometric and heat-resistant $\mathrm{Ce}_{0.1} \mathrm{~B}_{4.65} \mathrm{O}_{8.18}$ was synthesized by mild-hydrothermal method using homogeneous solutions of $\mathrm{Ce}\left(\mathrm{SO}_{4}\right)_{2}$ and $\mathrm{Li}_{2} \mathrm{~B}_{4} \mathrm{O}_{7} \cdot 5 \mathrm{H}_{2} \mathrm{O}$. The characterization was mainly based on semiquantitative analysis.

\section{References}

[1] V.N. Baumer, M.F. Dubovik, B.V. Grinyov, T.I. Korshikova, A.V. Tolmachev, A.N. Shekhovtsov, Radiat. Measur. 38, 359 (2004).

[2] Y. Fujimoto, T. Yanagida, H. Tanaka, H. Yokota, N. Kawaguti, K. Fukuda, D. Totsuka, K. Watanabe, A. Yamazaki, A. Yoshikawa, J. Cryst. Growth 318, 784 (2011).

[3] S.I. Hatamoto, T. Yamazaki, J. Hasegawa, M. Katsurayama, M. Oshika, Y. Anzai, J. Cryst. Growth 311, 530 (2009).

[4] W.W. Moses, M.J. Weber, S.E. Derenzo, D. Perry, P. Berhadl, L. Schwarz, U. Sasum, L.A. Boather, in: Proc. SCINT'97, Eds: Y. Zhiwen, F. Xiqi, L. Peijun, X. Zhilin, Chinese Academy of Science Press, Shanghai 1997 , p. 358.

[5] L. Zhang, C. Madej, C. Pedrini, C. Dujardin, J.C. Gacon, B. Moine, I. Kamenskikh, A. Belsky, D.A. Shaw, M.A. Mac Donald, in Ref. [4], p. 303.

[6] S.T. Lai, B. Chai, M. Long, R.C. Morris, J. Quantum Electron. 22, 1931 (1986).

[7] E.J. Popovici, M. Stefan, F. Lucaci, L. Muresan, E. Bica, E. Indrea, L. Tudoran, Phys. Procedia 2, 603 (2009).

[8] C. Feldmann, T. Justel, C. Ronda, P. Schmidt, Adv. Funct. Mater. 13, 511 (2003).

[9] M. Li, M. Wang, Z. Liu, Y. Hu, J. Wu, J. Rare Earths 27, 991 (2009).

[10] X. Zhang, H. Liu, W. He, J. Wang, X. Li, R. Boughton, J. Alloys Comp. 372, 300 (2004).

[11] S. Bhattacharyya, S. Ghatak, Ceram. Int. 35, 29 (2009).

[12] Y. Wu, J. Li, Y. Pan, Q. Liu, J. Guoa, Ceram. Int. 35, 25 (2009).

[13] T. Tachiwaki, M. Yoshinaka, K. Hirota, T. Ikegami, O. Yamaguchi, Solid State Commun. 119, 603 (2001).

[14] J.G. Li, T. Ikegami, J.H. Lee, T. Mori, J. Mater. Res. 15, 1514 (2000).

[15] X. Li, H. Liu, J.Y. Wang, H.M. Cui, F. Han, X.D. Zhang, R.I. Boughton, Mater. Lett. 58, 2377 (2004).

[16] G. Gözel, A. Baykal, R. Kniep, J. Solid State Chem. 129, 196 (1997).

[17] D.E.C. Corbridge, F.R. Tromans, Anal. Chem. 30, 1101 (1958). 